\title{
A Review on Epizootic Hemorrhagic Disease Virus (EHDV): An Emerging Constrain in Disease Management in Livestock Industry
}

\author{
Rath S S* \\ Department of Applied Microbiology, Utkal University, Bhubaneswar- 751004, India \\ *Corresponding author: Soumya Sankar Rath, Department of Applied Microbiology, \\ Utkal University, Bhubaneswar- 751004, India, Email: soumya.rath21@gmail.com
}

\section{Review Article}

Volume 2 Issue 7

Received Date: June 09, 2018

Published Date: June 20, 2018

\section{Abstract}

The world live-stock industry emerging by defeating all its limits and challenges in the course of mass production. Many pathogenic disease outbreaks restrict the scope for a better management practice rather to go for a better medication. Epizootic hemorrhagic disease virus (EHDV) can be considered as the major threat in the live-stock industry causing severe loss in the production as well as revenue generation. Several EHDV outbreak reports have been recorded along with immense research to understand the molecular mechanism of viral replication along with the structure, while a better management practice can strongly expect to prevent the subsequent infection. Several important characters directly or indirectly influence the EHDV outbreaks in different locations. The continuous disease occurrence and its significant impact on the livestock industry impose the conception of the management practice to prevent further consequences of EHDV infection.

Keywords: EHDV; White tailed deer; Elk; Cattle; Vaccine

\section{Introduction}

Epizootic haemorrhagic disease virus (EHDV) is one of the member of genus Orbivirus under the family Reoviridae. EHDV is well known as the causative agent of Epizootic hemorrhagic disease, which is an acute, infectious and fatal disease of ruminants [1]. It has a wide range of infection starting from domestic ruminants to wild ruminants including cervids, especially endemic white-tailed deer in North America and serious epidemics in wild and/or captive populations in many parts of the world. EHDV infection of wild and domestic ruminants has been reported in the America, Africa, Asia, Australia, the Middle East and some islands of the Indian Ocean. It affects primarily white-tailed deer (Odocoileus virginianus) and cattle and occasional deaths of some other animals. These epidemics resulted in significant economic losses from decreased productivity, including reduced milk yield. 
The first case of EHDV was reported at New Jersey and Michigan, United States in 1955, where several hundreds of white tailed deer were died [2]. There has been a wide distribution of EHD among the different locations of United States, while the frequency and severity occur infrequently in larger outbreaks resulting higher mortality in the northern United States. Likewise, higher survival rate with less severity can be noted in southern United States [3]. The occurrence of EHDV was first recorded in Japan in 1959 with the name of Ibaraki disease and become epidemic with a record death of over 50,000 death cases. There was a continuous outbreak report recorded over the different places in Japan [4].

The overall impact of EHDV on live-stock industry has increased with the increasing in the demand of live-stock industry and its products. Disease management, normally refers to a systematic population based approach emphasizing coordinated and comprehensive care along the variety of diseases and have many key components. The major key components in disease management involves; 1) the early identification of EHDV in all stages of disease; 2) improved animal health plan; 3) routine monitoring of the animals; 4) extending awareness about the EHDV infection and its symptoms among farmers. However, a proper animal health plan and routine monitoring can significantly reduce the mortality rate improving the animal health and will help in reducing the cost occur due to the huge mortality. Since there are many consequences of EHDV have been recorded with different time period in different geographical locations, this epidemiological review will contribute in the systemic identification of EHDV along with the effectiveness and efficiency of disease management.

\section{Molecular Morphology}

EHDV is a double- stranded RNA orbivirus composed of seven structural proteins (VP1 to 7) and divided into 10 segments [5]. The VP2 is the major outer coat protein and encoded by genome segment 2 (L2). The two major proteins VP2 and VP5 are involved in the virus's ability to attach to and penetrate a host cell, whereasVP7 forms the outer core layer and provide surface for VP2 and VP5 attachment. Likewise, the inner sub-core layer VP3 selfassembles to control the size and organization of the capsid structure and surrounds VP1, VP4 and VP6, in addition to the 10 linear double- stranded RNA segments [6]. The genome segment 3 (L3) and genome segment 7 codes for the structural protein VP3 and VP7 respectively [7]. The Genome segments 6 and 8 code for the NS1 and NS2, respectively [8]. Segment 10 codes for NS3 and NS3a, respectively. The genome segments, 1, 3, 4, 6 and 8 are the most highly conserved segment with more than $90 \%$ homology among EHDV serotypes [9].

There are 10 serotypes of EHDV have been distributed in worldwide [10]. The two Serotypes EHDV-1 (New Jersey strain) and EHDV-2 (Alberta strain) were first isolated in United States in a large scale mortality of white-tailed deer in the north- eastern and southern Alberta respectively. Additionally, topo types of EHDV-1 and EHDV-2 are present in Australia, which, although genetically divergent from analogous North American serotypes, share common neutralization epitopes $[11,12]$. IBAV, a topo type of EHDV-2 has been associated with periodic outbreaks in cattle in East Asia since its first description during a large-scale epizootic in Japan involving the mortality of 40,000 cattle in 1959 [13]. The three proposed serotypes EHDV-3, EHDV-4 and EHDV-6 were initially isolated from culicoides spp. in Nigeria, from cattle in Bahrain and from sentinel calves in the Sudan respectively [13,14]. EHDV serotypes 5,7 and8, along with the prototype strain of EHDV-6 (CSIR0753), were initially isolated from sentinel cattle herds in Queensland and the Northern Territory of Australia during 19771982 [15]. EHDV- 6, originate from Australia has been recognised as an emerging pathogen amongst cattle in several countries [16]. EHDV-6 was recovered from Kansas and Texas in 2008and become endemic. EHDV-7 was recently implicated in cattle outbreaks in Israel and although mortality rates were low (1\%), morbidity rates ranged from 5-80 \%, with clinical signs reported in 105different herds [17]. Two serotypes designated as EHDV-4 and an untyped isolate designated (EHDV-318) are enzootic in the Sudan [18]. In Australia, 5 serotypes designated as EHDV-5 through EHDV-8 were identified. In Nigeria, EHDV-3 and EHDV-4 were isolated from Culicoides spp [19].

\section{Pathogenesis}

Resembling many other viral diseases, EHDV cannot be transmitted from deer to deer or through any direct contact. EHDV must be transmitted via bites from Culicoides gnats (Culicoides verripennis). Livestock directly exposed to this disease rarely show signs of infection as there is no direct transmission yet livestock with EHDV show limited clinical symptoms like fever, loss of appetite, lameness and ulcers and crusty sores on the nose, mouth and teats [20]. Some other common clinical signs of EHDV in deer include the loss of fear of human, weakness, excessive salivation, bloody diarrhea, fever, rapid pulse and rapid respiration, Hemmorrhage and lack of oxygen which ultimately causes the blue appearance of the oral mucosa, similar to bluetongue disease [20]. There 
was a $20 \%$ mortality rate and $29 \%$ infection rate can be estimated in case of white- tailed deer [21]. Infected individuals are often found in bodies of water attempting lower their body temperature before dying and symptoms can be developed after seven days of exposure to the virus. The disease progresses with the common symptoms like discharge of blood like substances from nose and mouth and these lesions like substances are often consider as an indicator of the disease [22]. The symptoms may not be similar in all the case, however it can be classified into three forms of hemorrhagic disease: peracute, acute and chronic [23].

\section{Transmission}

Several studies have been conducted to find out the mode of transmission of the EHDV in deer. Although the mode of transmission can only be occurring when the deer inoculated to the infected material from diseased deer by subcutaneous, intramuscular, intravenous or oral routes in experimental settings. The tissues and organs vary from animal to animal while the most common organs are the heart, liver, spleen, kidney, lung and intestinal tract [22]. There may be no direct mode of transmission, while more often transferred through the biting fly (Culicoides), a small biting fly from family Ceratopogonidae [21]. The fly is most common in North America and found in damp areas. The female laid their eggs in wet and muddy areas and they hatch in between two to ten days after being laid. The small size of the fly aids in the spread and infection of the disease as they are difficult to trace [24]. The life cycle can be range from half a year to three years, while can produce several generations in a year. EHD can be more prominent to occur in late summer and early fall, specifically, midAugust through October are the most critical months for the disease. Likewise, it occurs faster in larger populations of deer and factors like severity of winter following the summer can impose the population of fly [23]. There can be different level of nucleotide sequence heterogeneity among the virus isolated from two different regions [25]. Disease control is difficult, as EHDV is spread by Culicoides midges, and commercial vaccines for cattle are only produced in Japan.

\section{Infection Pattern}

The proposed infection pattern in case of EHDV is quite similar to that of Influenza virus. The infection of viral particles enters to the cell through the endosomal route with the mechanism of acidification. The viral components are released to the cytoplasm with an early acidification of endosome. Early acidification of the endosome is thought to release components from the virus core. These components are then released into the host cell cytoplasm [26]. VP5 often catalyzes cell fusion, which facilitates the penetration of the endosomal membrane and consequently the release of outer capsid components [27]. EHDV does not contain large concentrations of VP5, yet it is still able to infect cell systems [28]. EHDV is able to be infectious due to the presence of VP7 as suggested by the binding of antibodies to the outer core protein VP7. The binding of EHDV to the cell surface via interaction of VP7 with glycosaminoglycans in addition to other receptors is the most probable entry mechanism [29].

The overall replication process is quite similar to other virus, however EHDV has to overcome specific set of problem during replication. The double- stranded RNA is unable to be used as template strand during mRNA translation using host cell machinery. Hence, EHDV required to bring its own transcription enzymes into the host cell to survive and synthesize the viral RNA and other proteins. The antiviral defence mechanisms are able to easily recognize and eliminate naked double-stranded RNA in the cell. The presence of the dsRNA would trigger antiviral mechanisms such as apoptosis and interferon production [30]. In order to avoid these host defences, EHDV hides their genome and other translation machinery within closed protein capsids and then these capsids are delivered into the host cell cytoplasm, where they initiate transcription [31].

\section{Diagnosis}

The infrequent increased EHDV occurrence in various locations requires to employ suitable detection technique yet several molecular techniques like Virus isolation, reverse transcriptase (RT) - PCR and real-time PCR are the most well-known technique for the detection of the EHDV. However, some common techniques like serology may be use for the determination of past infection and some other techniques like agar- gel immunodiffusion test (AGID, Complement fixation test (CFT), Enzyme-linked immunosorbent assay (ELISA), western blotting, PAGE, Nucleic acid hybridization and amplification technology, southern blot hybridization can be used for further detection of virus.

\section{Prevention}

The EHDV serotypes are transmitted from one country to another by animals and cause the widespread mortality, which led to huge loss in the live-stock industry. It has been listed as most important transmissible infectious disease. Prevention can only be controlled by the destruction of vector species of the 
insect but it is quite expensive and required more attention. The use of insect secured houses and insect repellents can be considered as a control measure. No proper vaccination available till date and quite difficult for the proper information about the different serotype. However, only successful EHDV2 vaccine is available in Japan to overcome the problem.

\section{Discussion}

Epizootic hemorrhagic disease virus (EHDV) is one of the fatal hemorrhagic infection in worldwide. Although there are different techniques has been developed for the early and rapid detection of the virus but there is less information and research work conducted due to the infrequent infection pattern. This imposes the higher risk of mortality in minimum time, where the case may be minor mortality to major mortality depending upon the serotype, geographical location and environmental conditions. There was a minor EHDV occurrence reported in Arizona (USA) by Noon et al, where two Mule deer (odocoileus hemionus) and one white- tailed deer (odocoileus virginianus) were affected with EHDV-2 [32]. The most common symptoms of EHD were observed in all the three deer [33]. The early infection symptoms were not familiar with farmers as it resembles with the other disease, simultaneously this may lead to larger outbreaks. In the summer and fall of 1993, an outbreak of EHDV-2 caused the death of 228 numbers of white-tailed deer [34]. A similar kind of report has been reported in southern Alberta, USA in September, 2013. The report indicated the presence of EHDV-2 in the white- tailed deer (Odocoileus virginianus) and three pronghorn antelope (Antilocapra americana). The EHDV-2 was identified by Reverse transcription- PCR and a total 50 number of deer died in the occurrence [35]. This report reveals the infection can not only appear in larger population but also in smaller populations, however the increasing occurrence of EHD virus in the different region indicates the dominance of the virus in live-stock industry. Both passive and active surveillance can be expected for a better monitoring procedure, which will contribute in studying the infection pattern and pathogenesis.

One of the major outbreaks have been reported in Michigan in summer and fall 2012 followed by 2010. The mortality rate of the white-tailed deer was 14,898 in 2012, which was 13 times more than the occurrence in 2010. Both the reports showed the possible cause of infection, which was the weather and climatic condition, deer population size and land type, however the result cannot be supported because of the identification of EHDV in other locations with different and same environmental and climatic conditions [36]. The conclusion from the outbreak suggested, there is no practical method for controlling the spread of disease rather to prevent the further spreading. Another important EHDV incident was reported in Israel during fall of 2006, where the EHDV serotype 7 caused a huge loss in the cattle industry resulting the subsequent loss to the dairy industry $[37,38]$. Mark et al., demonstrated an experiment determining the subsequent susceptibility of EHDV 7 on white tailed deer and observed the clinical sings of epizootic hemmoragic disease resulting $67 \%$ mortality [39]. This suggests the pathogenicity can retain for a longer period in multiple species with similar basic clinical signs.

A large number of EHDV mortality was reported in United States during summer and fall of 2012, including multiple species cattle (129 herds), captive white-tailed deer (65 herds), bison ( 8 herds), yak ( 6 herds) elk (1 herd) and sheep (1 flock). The average mortality withinherd morbidity was $7 \%$ in cattle and bison herds, and $46 \%$ in captive white-tailed deer herds and the average within-herd mortality in captive white-tailed deer herds was $42 \%$ [40]. However, the major observation can be found as high temperatures facilitate the transmission of EHD virus by $C$. sonorensis midges by decreasing the extrinsic incubation period of the virus.

Another observation was reported by Anbalagan et al., where the Epizootic hemorrhagic disease virus (EHDV) was isolated from a pregnant cow in Indiana, USA, exhibiting excessive salivation, pyrexia and abortion [41]. The VP2, VP5, and VP7 sequences of the isolated bovine EHDV showed 97.7, 97.4, and 97.9\% identity to a serotype-2 reference virus. Bovine EHDV was found to be closely related ( $>99.9 \%$ ) to white tailed deer (WTD) EHDV collected from Iowa in 2013 and showed less than $2.1 \%$ divergence from EHDV collected from WTD across the USA in 2013. The high degree of sequence identity between bovine and WTD EHDV isolates demonstrates that similar viruses concurrently circulate in both species.

The occurrence of EHDV during October to December, 2015 in Japan caused the mortality of 46 cattle showing the common symptoms like fever, anorexia, cessation of rumination, salivation and dysphagia. The Causative agent was the EHDV6 while it resembles the similar character with the serotype EHDV2 [42]. Similar Kind of occurrence observed in 2013 in the northwestern part of Kagoshima of Japan, where two cattle were affected with the common symptoms exhibited for EHDV [4]. The current live attenuated and inactivated vaccines against Ibaraki disease were developed based on Ibaraki-2 (EHDV2). 


\section{Virology \& Immunology Journal}

An experimental study was carried out by Pauline, during the outbreak in a captive facility housing whitetailed deer (Odocoileus virginianus), Bison (Bison Bison), Elk (Cervus elaphus), Cattle (Bos Taurus) and Goats (Capra hircus) in Colorado, USA [20]. The experimental result showed the EHDV infection in bison and elk in natural exposures still the roles of multispecies situation in EHDV infection remain unknown, which has been reported previously. There were no particular clinical signs observed in animal's neutralized EHDV infection other than the deer and simultaneously the neutralized EHDV-1 did not neutralize EHDV-2. Another experimental evidence showed the infection and viremia can occur in both bison and elk. The conclusion of the experiment reveals the EHDV infection in multiple species. Cattle can be serving as a reservoir for EHDV and many other orbivirus during the outbreak of EHDV in deer and other susceptible species allowing the further amplification of virus inside the host. There is another possibility of development of new infection resulting prior to the preliminary infection.

Considering the effect of environmental factor on the replication of EHDV in the vector, Mark et al., executed an experiment where the replication of EHDV-1, -2, and -7 in Culicoides sonorensis was accelerated by increasing temperature $[43,44]$. The result showed increasing temperature can shorten the incubation period for the EHDV serotype in C. sonorensis. Mark et al., emphasized the susceptibility of $C$. sonorensis towards EHDV-7 infection, which is a competent vector. The study reveals that $C$. sonorensis is susceptible to EHDV-7 infection and can transmit the virus to susceptible white-tailed deer, thus, $C$. sonorensis should be considered a potential vector of EHDV-7. However, the climatic variables can impact the Culicoides life cycle (particularly midge size and survival), virus replication within the midge, midge behavior, and midge distribution [44].

Feng et al., has developed a one- step multiplex RT-PCR assays system for the early identification of EHDV endemic serotype studying serotype distribution, emergence and evolution of EHDV [44]. In spite of this the assay can help in mapping distribution of EHDV outbreaks, estimating infection and mortality rates and monitoring changes in deer populations.

The minor and major EHDV outbreaks reveal the potency of the virus in the loss occurring in the world live-stock industry. The data and reports suggested the wide distribution of EHDV in worldwide, while the research studies suggest working more on the epidemiology and morphological structure of the virus. In many of the cases, the environmental and climatic conditions were same, while in some cases it is different. Simultaneously, the effect of vector was found to be more important in the spreading of disease; however, it is very difficult to control the vector due to the morphological character of the vector. Thus management of the disease is necessary for the early prevention of the disease decreasing the mortality rate. The study of the molecular expression of different EHDV serotype along with the different geographical locations will help in developing recombinant vaccine for a better disease management.

\section{Conclusion}

Several Viral diseases in live-stock industry creates a key impression on the mass production. EHDV is one of the major constrain in live-stock industry since a longer period of time, while the EHDV occurrence reports showed the vast effect on the live-stock industry for more than 50 years. Development of broad spectrum vaccine can be the solution to compete against EHDV infection; however, a better surveillance and monitoring procedure is strongly expected for the identification of the virus with prior post infection. The disease management approach must be advocated as a means of improving the effectiveness and efficiency of the vaccine and other medications.

\section{Acknowledgements}

This is a comparative review based on previous and present research work and I am thankful to the research work carried out by eminent researcher.

\section{Conflict of Interest}

There is no conflict of interest involved in this manuscript.

\section{References}

1. Aradaib I, Ali N (2004) Current Status and Future Prospects of Epizootic Haemorrhagic Disease of DeerA Review. Veterinarski Arhiv. 74 (1): 63-83.

2. Shope RE, Macnamara LG, Mangold R (1960) A virusinduced epizootic hemorrhagic disease of the virginia white-tailed deer (Odocoileus virginianus). J Exp Med 111(2): 155-170.

3. Gaydos JK, Davidson WR, Elvinger F, Howerth EW, Murphy M, et al. (2002) Cross-protection between 


\section{Virology \& Immunology Journal}

epizootic hemorrhagic disease virus serotypes 1 and 2 in white-tailed deer. J Wildl Dis 38(4): 720-728.

4. Hirashima Y, Kato T, Yamakawa M, Shirafuji H, Okano $\mathrm{R}$, et al. (2015) Reemergence of Ibaraki disease in southern Japan in 2013. J Vet Med Sci 77(10): 12531259.

5. Mecham Jo, Dean Vc (1988) Protein Coding Assignment for the Genome of Epizootic Haemorrhagic Disease Virus. The Journal of General Virology 69 (Pt 6): 1255-1262.

6. Anbalagan S, Hause BM (2014) Characterization of Epizootic Hemorrhagic Disease Virus from a Bovine with Clinical Disease with High Nucleotide Sequence Identity to White-Tailed Deer Isolates. Arch Virol 159(10): 2737-2740.

7. Aradaib IE, Willson WC, Schore CE, Mohammed MEH, Cullor JS, et al. (1998) PCR detection of North American and Central African Isolates of epizootic hemorrhagic disease virus based on genome segment 10 sequence analysis of EHDV-1. J Clinical Microbiol 36(9): 2604-2608

8. Aradaib IE, Karrar AE, Ibrahim KEE, Osburn BI (1999) Detection of orbivirus infection. Sudan J Vet Sci Anim Husb 37: 1-29.

9. Wilson WC, Fukusho A, Roy P (1990) Diagnostic complementary DNA probe for genome segment 2 and 3 of epizootic hemorrhagic disease virus serotype 1. Am J Vet Res 51(6): 855-860.

10. Gorman BM (1992) An overview of the orbiviruses. Proc. of the 2nd International Symposium on bluetongue, African horse sickness and related Orbiviruses, (Walton T. E., B. I. Osburn, Eds.). CRC press Inc, Boca Raton, Florida pp: 335-347.

11. Gould AR, Pritchard LI (1991) Phylogenetic analyses of the complete nucleotide sequence of the capsid protein (VP3) of Australian epizootic haemorrhagic disease of deer virus (serotype 2) and cognate genes from other orbiviruses. Virus Res 21(1): 1-18.

12. Weir RP, Harmsen MB, Hunt NT, Blacksell SD, Lunt RA, et al. (1997) EHDV-1, a new Australian serotype of epizootic haemorrhagic disease virus isolated from sentinel cattle in the Northern Territory. Vet Microbiol 58(2-4): 135-143.
13. Anthony S, Maan N, Maan S, Sutton G, Attoui H, et al. (2009) Genetic and Phylogenetic Analysis of the Core Proteins Vp1, Vp3, Vp4, Vp6 and Vp7 of Epizootic Haemorrhagic Disease Virus (EHDV). Virus Research 145(2): 187-199.

14. Lee VH, Causey OR, Moore DL (1974) Bluetongue and related viruses in Ibadan, Nigeria: isolation and preliminary identification of viruses. Am J Vet Res 35(8): 1105-1108.

15. St George TD, Cybinsky DH, Standfast HA, Gard GP, Della-Porta AJ (1983) The isolation of five different viruses of the epizootic hemorrhagic disease of deer serogroup. Aust Vet J 60(7): 216-217.

16. Allison $\mathrm{AB}$, Goekjian $\mathrm{VH}$, Potgieter $\mathrm{AC}$, Wilson $\mathrm{WC}$, Johnson DJ, et al. (2010) Detection of a novel reassortant epizootic hemorrhagic disease virus (EHDV) in the USA containing RNA segments derived from both exotic (EHDV-6) and endemic (EHDV-2) serotypes. Journal of General Virology 91(Pt 2): 430439.

17. Yadin H, Brenner J, Bumbrov V, Oved Z, Stram Y, et al. (2008) Epizootic haemorrhagic disease virus type 7 infection in cattle in Israel. Vet Rec 162(2): 53-56.

18. Mohammed ME, Mellor PS (1990) Further studies on bluetongue and bluetongue-related Orbiviruses in the Sudan. Epidemiol Infec 105(3): 619-632.

19. Moore DL (1974) Bluetongue and related viruses in Ibadan, Nigeria: serologic comparison of bluetongue, epizootic Hemorrhagic disease of deer, and Abadina (palyam) viral isolates. Am J Vet Res 35(8): 11091113.

20. Nol P, Kato C, Reeves WK, Rhyan J, Spraker T, et al. (2010) Epizootic Hemorrhagic Disease Outbreak in a Captive Facility Housing White-Tailed Deer (Odocoileus virginianus), Bison (Bison bison), Elk (Cervus elaphus), Cattle (Bos taurus), and Goats (Capra hircus) in Colorado, USA. Journal of Zoo and Wildlife Medicine 41(3): 510-515.

21. Savini G, Afonso A, Mellor P, Aradaib I, Yadin H, et al. (2011) Epizootic Heamorragic Disease. Research in Veterinary Science 91(1): 1-17.

22. Schmitt Stephen M (2012) Summary of Selected Michigan Wildlife Health Issues. Michigan Department of Natural Resources. 
23. Epizootic Hemorrhagic Disease (Ehd) In White-Tailed Deer (2013) Michigan Department of Natural Resources.

24. Sanders CJ, Shortall CR, Gubbins S, Burgin L, Gloster J, et al. (2011) Influence of Season and Meteorological Parameters on Flight Activity of Culicoides Biting Midges. Journal of Applied Ecology 48(6): 1355-1364.

25. Murphy MD, Hanson BA, Howerth EW, Stallknecht DE (2006) Molecular Characterization of Epizootic hemorrhagic disease virus serotype 1 associated with a 1999 epizootic in white tailed deer in the eastern United States. Journal of Wildlife diseases 42(3): 616624.

26. Hyatt AD, Zhao Y, Roy P (1993) Release of bluetongue virus-like particles from insect cells is mediated by BTV non-structural protein NS3/NS3A. Virology 193(2): 592-603.

27. Zhou EM, Chan MKH (1996) Immunoblot assay as a confirmatory test of competitive ELISA for serodiagnosis of bluetongue. Journal of Veterinary Diagnostic Investigations 8: 365-367.

28. Mertens PP, Burroughs JN, Walton A, Wellby MP, Fu $\mathrm{H}$, et al. (1996) Enhanced infectivity of modified bluetongue virus particles for two insect cell lines and for two Culicoides vector species. Virology 217(2): 582-593.

29. Wilson WC, O'Hearn ES, Tellgren-Roth C, Stallknecht DE, Mead DG, et al. (2009) Detection of All Eight Serotypes of Epizootic Hemorrhagic Disease Virus by Real-Time Reverse Transcription Polymerase Chain Reaction. J VET Diagn Invest 21(2): 220-225.

30. Goldbach R, Bucher E, Prins M (2003) Resistance mechanisms to plant viruses: an overview. Virus Res 92(2): 207-212.

31. Jacobs BL, Langland JO (1996) When Two Strands Are Better Than One: The Mediators and Modulators of the Cellular Responses to Double-Stranded RNA. Virology 219(2): 339-349.

32. Noon TH, Wesche SL, Heffelfinger J, Fuller A, Bradley GA, et al. (2002) Hemorrhagic Disease in Deer in Arizona. Journal of Wildlife Diseases 38(1): 177-181.

33. Gaydos JK, Crum JM, Davidson WR, Cross SS, Owen SF, et al. (2004) Epizootiology of an Epizootic
Hemorrhagic Disease Outbreak in West Virginia. Journal of Wildlife Diseases 40(3): 383-393.

34. Pybus MJ, Ravi M, Pollock C (2014) Epizootic Hemorrhagic Disease in Alberta, Canada. Journal of Wildlife Diseases 50(3): 720-722.

35. Schrauben MA (2013) 2012 Epizootic Hemorrhagic Disease in White-tailed Deer in Michigan: History, Consequences, and Predictions. Honors Projects pp: 194.

36. Kedmi M, Van Straten M, Ezra E, Galon N, Klement E (2010) Assessment of the productivity effects associated with epizootic hemorrhagic disease in dairy herds. Journal of Dairy Science 93(6): 24862495.

37. Kedmi M, Herziger Y, Galon N, Cohen RM, Perel M, et al. (2010) The association of winds with the spread of EHDV in dairy cattle in Israel during an outbreak in 2006. Prev Vet Med 96(3-4): 152-160.

38. Ruder MG, Howerth EW, Stallknecht DE, Allison AB, Carter DL, et al. (2012) Vector competence of Culicoides sonorensis (Diptera: Ceratopogonidae) to epizootic hemorrhagic disease virus serotype 7 . Parasites Vectors 5: 236.

39. Stevens G, McCluskey B, King A, O'Hearn E, Mayr G (2015) Review of the 2012 Epizootic Hemorrhagic Disease Outbreak in Domestic Ruminants in the United States. PLoS ONE 10(8): e0133359.

40. Kamomae Y, Kamomae M, Ohta Y, Nabe M, Kagawa Y, et al. (2015) Epizootic Hemorrhagic Disease Virus Serotype 6 Infection in Cattle, Japan. Emerging Infectious Diseases 24(5): 902-905.

41. Anbalagan S, Cooper E, Klumper P, Simonson RR, Hause BM (2014) Whole Genome Analysis of Epizootic Hemorrhagic Disease Virus Identified Limited Genome Constellations and Preferential Reassortment. The Journal of General Virology 95 (2): 434-441.

42. Ruder MG, Stallknecht DE, Howerth EW, Carter DL, Pfannenstiel RS, et al. (2015) Effect of Temperature on Replication of Epizootic Hemorrhagic Disease Viruses in Culicoides sonorensis (Diptera: Ceratopogonidae). J Med Entomol 52(5): 1050-1059.

43. Ruder MG, Allison AB, Stallknecht DE, Mead DG, McGraw SM, et al. (2012) Susceptibility of White- 
Tailed Deer (Odocoileus Virginianus) to Experimental Infection with Epizootic Hemorrhagic Disease Virus Serotype 7. Journal of Wildlife Diseases 48(3): 676685.
44. Sun F, Cochran M, Beckham T, Clavijo A (2014) Molecular Typing of Epizootic Hemorrhagic Disease Virus Serotypes by One-Step Multiplex RT-PCR. Journal of Wildlife Diseases 50(3): 639-644.

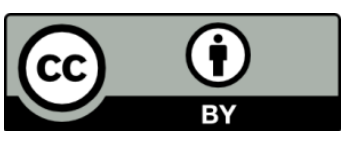

